\title{
Chaos Models And The Monetary Dynamics Of Hyperinflation
}

Punita Rao, Post Doctorate Research, Clute Institute, Littleton, USA; University of Mumbai, India

\begin{abstract}
Modern methods of qualitative analysis of dynamic systems go back nearly a century to Poincare (1880, 1892). Since the classic work of Smale (1967), it has become clear that very complicated, or chaotic, trajectories (time path) can easily arise in certain dynamic systems and that such complicates trajectories can persist when small perturbations of the underlying systems occur. Such a phenomenon, referred to as chaos, a case that is emphatically not pathological, is essentially one in which a dynamic mechanism that is very simple, and, above all, deterministic yields a time path so complicated that it will invariably pass all the standard tests of randomness. The seminal contribution of Lorenz (1963), Li and Yorke (1975), May (1976), Stefan (1977), amongst others have greatly facilitated an exploration of the pertinence of such complicated dynamics, arising in simple first order dynamic non-linear systems, to a variety of fields, including physics, biology, ecology and of late economics. In the context of the above literature and the development thereafter we intend to build the model that comprises of four equations. These specific: (1) The demand for real balances, (2) The money- inflation link, (3) the government budget deficit, and (4) the inflation tax revenue. The reduced form of the model is seen to yield a three parameter system whose phase diagram for the inflation rate (expressed in terms of a transcendental equation) produces solutions which are capable of generating stable, cyclic, or chaotic behavior.
\end{abstract}

Keywords: Hyperinflation; Chaos Models; Monetary Dynamics

\section{INTRODUCTION}

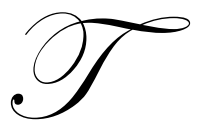

he origin of interest in complex economic dynamics are to be found in the works of Frisch (1933), lundberg (1937) and Samuelson (1939), who used difference equations, differential equations and mixed models to generate deterministic time paths. It was readily demonstrated that any parameter values chosen within broad ranges (that could sometime be easily calculated) for such a class of linear models must yield an oscillatory time path. However, unlike their predecessors, the underlying logic of these models was easy to grasp and it was not difficult to intuitively explain the economic underpinnings of the oscillatory mechanism.

These models were received enthusiastically at first and generated much subsequent literature. Still, before long, an aura of disillusionment seemed to creep in for two basic reasons. First, it became quite clear that the behaviour of the time path generated by such linear dynamic system could be extremely sensitive to the changes in the value of the parameters, as well as the structure of the model. That made it extremely difficult to formulate models and econometric estimates of their parameters which could be said to constitute robust and realistic representations of reality. Such sensitivity, though of a rather different nature, holds with even greater intensity for chaos models, and it is one of the main reasons for their interest.

Second, it was recognized quite early that, qualitatively speaking, all such linear models were essentially capable of generating only four basic types of time paths: 1 oscillatory and stable; 2 oscillatory and explosive; 3 non-oscillatory and stable; and 4 non-oscillatory and explosives. It was soon recognized that even extremely complex linear equations of much higher order would not $\mathrm{b}$ able to generate any time path substantially different from these four. This limited range of possible configuration was not sufficiently rich from an economics point, 
since it was readily agreed that in reality time paths are often more complicated and many oscillations do not seems to either explode or dampen towards disappearance.

A solution to this problem was proposed by Hicks (1950) and Goodwin (1951) with the explicit introduction of non linear models of this general form: $\mathrm{Y}(\mathrm{t})=\mathrm{f}(\mathrm{Y}(\mathrm{t}-1), \ldots \mathrm{y}(\mathrm{t}-\mathrm{h}))$, where $\mathrm{Y}(\mathrm{t})$ refers to the output at time $t$ and $f$ is the function possibly nonlinear in all its argument. Responding to real economic issues and not merely to formal mathematical tractability, these authors showed that such a nonlinear model can yield a stable limit cycle towards which all possible time paths of the variable $\mathrm{Y}(\mathrm{t})$ would converge. That is, rather than converging to a fixed equilibrium value $\mathrm{Y}^{*}$, with the oscillation damping out towards a zero amplitude, the nonlinear models could instead yield a stable equilibrium cycle with $\mathrm{Y}(\mathrm{t})$ forever wandering from peak to trough along the equilibrium cyclical mode. This was pretty much where matters were left off, with the work stopping just short of explicitly introducing a degree of nonlinearity sufficiently intense to generate totally chaotic behaviour.

\section{CHAOS THEORY}

In essence, chaos theory was able to demonstrate that even a very simple relationship that is totally deterministic but nonlinear such as the first order nonlinear difference equation can yield an extremely complex time path. Intertemporal behaviour can acquire an appearance of disturbance by totally random shocks and can undergo violently abrupt changes with the passage of time or with extremely small changes in the parameter values or with equally minute changes in the initial conditions, so that the resulting chaotic trajectories can past almost all the standard tests of randomness which are unable to distinguish such chaotic patterns from truly random behaviour. Moreover, such chaotic trajectories sometimes never return to any point previously traversed, but display over a bounded region, often referred to as an "attractor" a "disorderly" oscillatory pattern.

Where chaos occurs, economic forecasting becomes extremely difficult because the two basic projection techniques - time- extrapolation and econometric forecasting - both break down. Extrapolation models, at any level of sophistication, are totally inadequate because they just cannot handle one of the most characterizing attributes of chaotic trajectories- their propensity to introduce sharp and unheralded qualitative breaks at randomly determined intervals along the time path. Econometric forecasting also runs into similar problems because in projecting chaotic trajectories, there is a latent possibility that evens a minute error in calculation, either of a parameter value or in an initial condition, can completely alter the qualitative characteristics of the forecasts beyond recognition.

\subsection{The Mathematics of Chaos}

Much of the discussion that follows will attempt to provide an alternative framework for explaining the phenomenon of chaos in economics; let us briefly define within the accepted paradigm of a hill-shaped phase diagram the concepts of cyclical and oscillatory behaviour so that the theoretical underpinnings of chaotic trajectories are clearly established.

A time path, $\mathrm{x}(\mathrm{t})$, will be taken to be characterized by a cycle whose duration is p periods if it always replicates itself precisely every p periods from any initial points in its trajectory, and does not do so in any smaller number of periods. Thus, any pattern which repeats itself exactly every p periods is said to be a p- period cycle. In contrast, an oscillatory time path is defined as one which is not monotonic, but in which the time path never replicates any earlier portion of the trajectory.

The simplest and most common chaos model involves a nonlinear first- order one- variable difference equation of the form: $x(t+1)=f(x(t))$, whose phase diagram, showing $f(x(t))$ as a function of $x(t)$, in a hill shaped and "tunable": in other words, the height, steepness and location of the hill can be adjusted as desired by a suitable modification in the values of the parameters of $f(x(t))$. This phase diagram is the geometric analogue used to analyse the time path generated by a difference equation model, and has been widely employed in chaos analysis. The functional representation most commonly invoked in order to illustrat the phenomenon of chaos, either in mathematics or economics, is the 'inverted parabola' defined by the quadratic equation with a single parameter. R, given by 
$\mathrm{x}(\mathrm{t}+1)=\mathrm{F}(\mathrm{x}(\mathrm{t})=\mathrm{rx}(\mathrm{t})(1-\mathrm{x}(\mathrm{t}))$

In order to provide meaningful insights into the chaotic dynamics inherent in the above equation, the following two conditions must be satisfied:

$0<\mathrm{x}(0)<1 ;$ and $0<\mathrm{r} \leq 4$

The phase curve is defined as a graph of eq. (2.1.1), for a given fixed value of $r$, and expresses $x(t+1)$ as a function of $x(t)$. The slope of this phase curve is given by

$\mathrm{dx}(\mathrm{t}+1) / \mathrm{dx}(\mathrm{t})=\mathrm{r}(1-2 \mathrm{x}(\mathrm{t}))$

We see from eq. (2.1.1) that whatever be the value of $r$, the phase curve must always reach its maximum at $x(t)=0.5$ at which point its slope given by eq. (2.1.2), should be equal to zero. At that point, its height is equal to $\mathrm{r} / 4$ which increases in direct proportion to $r$. This, it is seen that the insight of the phase diagram as well as its slope, which ultimately determines the equilibrium value of $\mathrm{x}$, denoted by $\mathrm{x}^{*}$, is crucially linked to the parameter $\mathrm{r}$ of the difference equation. This is because, we must have $\mathrm{x}(\mathrm{t}+1)=\mathrm{x}(\mathrm{t})=\mathrm{x} *$ so that

$\mathrm{x}^{*}=\mathrm{rx} \mathrm{x}^{*}\left(1-\mathrm{x}^{*}\right)$ or $\left.\mathrm{x}^{*}=1-1 / \mathrm{r}\right)$

Moreover from eq.(2.1.2) and (2.1.3), we note that the slope of the phase graph at equilibrium is given by

$r\left(1-2 x^{*}\right)=r(1-2\{1-(1 / r)\})=2-r$

This analysis provides for four general cases:

1. if $\mathrm{o}<\mathrm{r} \leq 1$, there will be no positive equilibrium level as $\mathrm{x}^{*}=1-(1 / \mathrm{r}) \leq 0$ but if $\mathrm{r}>1$, there will be positive value equilibrium point;

2. if $1<\mathrm{r} \leq 2$, the slope of the phase curve at equilibrium, given by $2-r$, will be non-negative

3. if $2<r<3$, that slope will be negative but less than unity in absolute value; and

4. if $3 \leq r \leq 4$, the absolute value of the slope will be equal or greater than unity.

For two basic reasons, this last case is the one that has held interest of mathematicians for more than a quarter of a century. First, since the slope of the phase curve at equilibrium is negative, the theory of difference equations tells us that the time path of $\mathrm{x}(\mathrm{t})$ must be oscillatory. Second, since the slope is not less than unity in absolute value, these cob - web like oscillations will be explosives with ever- increasing amplitudes Had the graph not been hill- shaped, this would have implied moving ever further away from the equilibrium value, $x^{*}$, in the neighborhood of the value of $x$. However, with a hill -shaped phase curve, as the cobweb expands, $x(t)$ will encounter the positive sloping side of the hill and 'bounce off it' towards an $x(t+1)$ value closer to the equilibrium level, $x^{*}$, than before. Such a return towards equilibrium must occur but when this happens it can only be temporary because, as $\mathrm{x}(\mathrm{t})$ starts zeroing on $\mathrm{x}^{*}$, it will again encounter that portion of the phase curve whose slope is equal to or greater than unity in absolute value, leading once more to oscillations away from equilibrium. Under such circumstances, the time path can turn out to be extremely complex, as chaos behaviour is seem to follow some very simple and orderly rules. To understand the nature of "orderly" pattern, it is necessary to emphasize that the ensuing discussion is base entirely on our chaos model given by eq. (2.1.1), whose phase graph is hill- shaped. However it will later been shown that the existence of a hill- shaped phase graph is not a necessary condition for explaining chaos behaviour which is also seen to arise within the framework;: a first-order non- linear (transcendental) relationship of the form $\mathrm{x}(\mathrm{t}+1)=\mathrm{f}\left\{\mathrm{e}^{\mathrm{x}(\mathrm{t})}\right\}$, whose phase graph, which is not hill- shaped allows for more complex interactions, including the existence of several equilibria, by suitable adjustments of parameter values.

Consider eq. (2.1.1), while, for any given value of the parameter, $r$, there is at most one 'stable cycle, the cycle that is stable as $r$ increases. For $0<r \leq 1$, the stationary solution of the equation, defined as a sequence $(x(t))$ which is a solution of eq.(2.1.1) and is such that $\gamma_{t}, \mathrm{x}(\mathrm{t})=\mathrm{x}^{*}$ for some $\mathrm{x}^{*}$ such that $0 \leq \mathrm{x}^{*} \leq .1$, at the origin is stable Thus a stationary solution is a cycle of period 1 . If $1<\mathrm{r} \leq 2$, the time path will be non-oscillatory while if $2<\mathrm{r}<3$, 
the time path will be oscillatory. However, in both these cases, the trajectories will eventually converge, regardless of the initial condition, $x(0)$, selected, to a stable equilibrium point, $x^{*}=1-(1 / r)$. Thus, the stationary solution is stable and $\mathrm{x}^{*}$ is a fixed point of the function $\mathrm{f}(\mathrm{x}(\mathrm{t}))$.

At $r=3$, however, the system undergoes a bifurcation. That is, there is a change in the structure of the set of solutions.. For r. 3, the solution of $x^{*}=1-(1 /$ r) is no longer stable and the resulting time path will be replaced by one which converges to a stable limit two- period cycle. That is, in this region, for any arbitrary initial condition, the system will eventually settle down into a cycle of period two then, as $r$ increases further (to approx 3.4495), there occurs essentially a repeat of what happened at $r=3$. The two period cycle becomes unstable and, in turn, gives rise to a stable four period cycle. This process is known as a period- doubling bifurcation. As the value of $r$ is increased further, this four- period cycle itself becomes unstable in its turn, and from each of the four equilibrium values that formerly constituted the four period cycle, two additional points emerge via a new bifurcation. These new eight points now constitute a stable eight period cycles. As $r$ is increased, the system goes through an infinite number of such period- doublings and stable cycles of length $16,32,64 \ldots \ldots, 2^{n}$, successively appear and become unstable. Ultimately, the time path must involve an infinite number of cycle lengths.

At first, these cycles will have only even periods of increasing length, all of them being powers of two. Eventually, at a limit point of the parameter $r$, which is about $x^{*}=3.57$, cycles whose length involve an odd number of periods will appear and the first such odd- period cycle to enter the time path will be very long. However, they are soon joined by odd- period cycles of shorter and shorter duration, ultimately encompassing every positive odd integer except three. Finally, at some value of the controlling parameter r, even three- period cycles will occur. At this junction, there will be an uncountable number of initial values yielding bounded time paths which never repeat past behaviour, no matter how long a set of time periods the interactions are continued. When, this set of conditions holds, we say that the chaos is present. This is the famed $\mathrm{Li}$ - York theorem ( $\mathrm{Li}$ and York 1975) whose conjecture and proof of the proposition that "Period Three Implies Chaos" forms the cornerstone of much of the work of chaos theory.

The order in which the cycles appear follows Sarkovskii's characterization of natural numbers. We define Sarkovskii's ordering of the positive integers as follows

$$
\begin{aligned}
& 1<2<4<\ldots<2^{\mathrm{k}}<2^{\mathrm{k}+1}<\ldots \ldots<2^{\mathrm{k}+1}(2 \mathrm{~m}+1)<2^{\mathrm{k}+1}(2 \mathrm{~m}-1) \\
& <\ldots 2^{\mathrm{k}+1}(5)<2^{\mathrm{k}+1}(3)<\ldots \ldots<2^{\mathrm{k}}(2 \mathrm{~m}+1)<2^{\mathrm{k}}(2 \mathrm{~m}-1)<\ldots<2^{\mathrm{k}}(5)<2^{\mathrm{k}}(3)<\ldots \ldots<2(2 \mathrm{~m}+1)<2(2 \mathrm{~m}-1)<\ldots .2(5)<2(3) \\
& <\ldots \ldots<(2 \mathrm{~m}+1)<(2 \mathrm{~m}-1)<5<3 .
\end{aligned}
$$

Sarkovskii's Theorem: If $\mathrm{f}$ is a continuous map of an interval into itself with a p-period cycle and $\mathrm{q}<\mathrm{p}$ in Sarkovskii 's ordering then $\mathrm{f}$ has a q period cycle. It can be seen from the theorem that in the nonlinear case it is possible to get an infinite number of cycles of different periods even with a first- order difference equation provided that there is an odd- period cycle. Thus, Sarkovskii's ordering starts with $1<2<4<\ldots<2^{\mathrm{k}}<\ldots$. First, we get a fixed point, then a 2 period cycle, followed by a 4 - period cycle. In particular, when there is a 3 -period cycle, there must be cycles of all other periods.

Since all the cycles before $\mathrm{x}^{*}$ had been attained from period- doubling bifurcations, they all have periods that are power of 2 (i.e for some r, the period was equal to 2). In fact, between $3 \leq r \leq 4$, stable cycles of all $p$ periods can be seen. The behaviour of 3-period cycle is fairly typical. As $r$ approaches a value at which a 3-period cycle appears, a phenomenon knows as intermittent chaos occurs. In this, the system essentially alternates between following an approximate 3-period cycle and chaotic behaviour. Thus, as $r$ is increased, a stable 3-period cycle appears. It should be made clear, however, that while an infinite number of cycle lengths are present now, they need not in general be all equally influential upon the time path. Like the earlier cycles the 3-period cycle undergoes a change of period doubling bifurcations as $r$ is increased still further. It is successively replaced by a stable cycle of period $6,12,24 \ldots \ldots 2^{\mathrm{n}}(3)$,

These bifurcations accumulate at a limit point where the behaviour is similar to that at $\mathrm{r}^{*}=3.57$ (which was the limit point of the period doubling sequence following the 2 - period cycle). After the limit point, the system returns to chaotic behaviour. The set of $r$ - values from the beginning of the 3 - period cycle to the limit point of the 
sequence of the bifurcations is known as a period doubling window. Between $3 \leq r \leq 4$, there are, in theory, period doubling windows containing cycles of all possible lengths. Clearly, most of these period doubling windows occupy a very small interval in the parameter space. In numerical simulation, the only period doubling window that can be seen are those starting with cycles of relatively short periods such as 3,5 or 7.

\section{ECONOMIC APPLICATION OF CHAOS THEORY}

Chaos theory thus seems to have the power in providing caveats for both economic analysis as well as policy designer. For example, it warns us that apparently random behaviour may not be random at all. It demonstrates dramatically the dangers of extrapolation based on existing techniques which are ill equipped to handle chaos. It highlights the difficulties that can beset forecasting based on existing econometric models which are not sufficiently accurate to unambiguously guarantee that the qualitative character of the forecast has not been structurally changed beyond recognition by a very minute error in calculation. It has provided the basis for the construction of simple models of the behaviour of rational agents, showing how even these can yield extremely complex developments. It has served as the source for models of learning behaviour besides being shown to arise naturally in a number of standard general equilibrium models. Finally it has provided invaluable insights about the source of oscillations in a number of economic models.

In economics, the possibility of cyclical and chaotic dynamic behaviour was perhaps first suggested by May and Beddington (1975). It was then shown to arie in duopoly models (Rand 1978); macroeconomic models (Stutzer 1980); dynamic models of choice with endogenous tastes(Benhabib and Day 1981); cobweb models of demand and supply(Jenson and Urban 1982); models of productivity growth(Baumol and Wolf 1983); and growth cycle models(Dane and Malgrade 1984). Cycle and chaotic dynamics have been shown to arise in a number of competitive models of intertamporal general equilibrium. These results are of particular interest since they demonstrates that prices and output can oscillate even under standard competitive assumptions such as market clearing, perfect information and perfect foresight. For overlapping generation model of exchange, Benhabib and day (1982) provided sufficient conditions for cyclic and chaotic dynamics under perfect foresight when the young are net borrowers while Grandmont (1986) studied the case where the young are net savers and provided sufficient condition to correctly forecast periodic eqilibria. Boldrin and Montracchio (1986) showed that chaotic trajectories can occur even in equilibrium models with infinitely lived agents.

Almost all the chaotic economic models mentioned above employ one dimensional (i.e single variable first order) difference equation. One exception is the paper by Benhabib and Day (1981) which studies the dynamics of endogenous choice and provides conditions on preferences under which chaotic choice sequence of $n$ - commodity vectors arise. These use the results of Diamond (1976) which generalize the Li and Yorke (1975) proposition to the $\mathrm{n}$ - dimensional (n- period lag) case. However these results are not easy employ and their use up to now has been limited. They only suggest the conjecture that in the higher order systems, sufficient conditions for chaos to arise are easier to satisfy than in the case of first- order system, i.e., chaos is more likely to occur in higher order systems.

The evidence hitherto makes it quite clear that chaos theory does have an enormous potential for explaining various economics phenomenon (Rao 1990). Two of the most striking features of any macroeconomic data are their cyclical character and the random like noise superimposed upon these cycles, which are seen to range from short run business cycles to long run kondratiev waves. Despite the many attempts to explain them conventionally (Lucas 1975) or using chaos theory, there is still an impression amongst mathematical economists that something further could be said about business cycles. It is towards this end that the following monetary model has been developed in order to explain the chaotic dynamics of hyperinflation - which is at one extreme end of the spectrum associated with business cycle.

\section{THE MONETARY DYNAMICS OF HYPERINFLATION}

The key to the theoretical specification of a chaos theory model of self- generating inflation, specified in terms of a transcendental equation, in which real cash balances and prices are seen to exhibit chaotic behaviour during hyperinflation lies in the construction of a ladle- shaped phase graph which forms a clear departure from the accepted paradigm of a hill- shaped phase diagram. Such an interesting specification, which assumes three 
controlling parameters, leads us to hypothesize the possible of three equilibrium solutions along the phase diagram which, depending upon the values assumed by these parameters, could be stable (with the price changes converging towards a fixed point of cyclic equilibrium) or unstable (with the price changes oscillating chaotically after the initial self generating process) exactly in the manner that Cagan had conjectured.

Section 4.1 discusses the formulation of the money demand function in which it is hypothesized that variation in the real balances mainly depends on variation in the rate of inflation. Section 4.2 provides the moneyinflation link setting up the dynamically unstable process by means of which money supply fuels inflation. Section 4.3 defines the government budget deficit and relates it with the growth of money supply. Section 4.4 analyzes the revenue collected from the tax on real balances as a consequence off inflation, i.e. the inflation tax revenue and links it up with deficit, money growth and inflation. The final provides the specification of a dynamic model in which current price movements influences future price changes in the manner reminiscent of a chaotic process.

\subsection{The demand for real balances}

During hyperinflation, the amount of real balances held by the public changes drastically. These changes seem to reflect changes in the preferences of individuals for real balances i.e. shift in the money demand function. However, these changes actually reflect the variations in the variable that affect the desired level of real balance. One of the major variables affecting the demand for money- real income- seems to be relatively stable during hyperinflation compared with the large fluctuations in real money demand. Thus, to account for these oscillations as a movement along the money demand function instead of a shift in the money demand function, we must look for large changes in the remaining variables expected to influence money demand: the opportunity cost of holding money instead of other assets in the overall wealth portfolio.

The only opportunity cost that seems to fluctuate widely enough to account for the drastic changes in real balances during hyperinflation is the rate of inflation. This suggests the hypothesis that changes in real balances during hyperinflation result slowly from variations in the rate of change of prices. Hence, an equation of the following form is able to account for most of the changes in the real money demand during hyperinflation:

$\mathrm{M} / \mathrm{P}(\mathrm{t})=\mathrm{e}^{-\mathrm{bp}(\mathrm{t})}$

Here, $\mathrm{M} / \mathrm{P}(\mathrm{t})$ is the real money demand in time period $\mathrm{t}$, where $\mathrm{t}$ is reckoned in terms of month, $\mathrm{e}$ is the base of all natural logarithms, $\mathrm{p}(\mathrm{t})$ is the rate of inflation in time period $\mathrm{t}$, and $\mathrm{b}$ (which must be positive) is a constant. The elasticity of demand for real balances with respect to the rate of inflation is $-b p$.

\subsection{The money inflation link}

Any function such as eq. (4.1.1) that relates real balances to the rate of inflation essentially implies instability. This can be seen by initially re writing eq. (4.1.1) in terms of logarithms and then differentiating the result with respect to prices, $\mathrm{P}(\mathrm{t})$. Under the assumption the money supply $\mathrm{M}(\mathrm{t})$, is independent of prices. i.e. $\mathrm{dM}(\mathrm{t}) / \mathrm{dP}(\mathrm{t})=0$. This yields

$\{\mathrm{dp}(\mathrm{t}) / \mathrm{dP}(\mathrm{t})\}=(1 / \mathrm{b})\{1 / \mathrm{P}(\mathrm{t})\}>0$

Hence, as the partial derivative is positive, an increase in the rate of inflation occurs whenever prices rise. Thus, the inflation will continue under its own momentum which implies that $\mathrm{p}(\mathrm{t}+1)>\mathrm{p}(\mathrm{t})$, for all $\mathrm{t}$ (4.2.2). During hyperinflation, the rates of money growth $(\mathrm{M} / \mathrm{M}=\mathrm{m})$ are very high, although they are not of the same order as the rates of inflation $(\mathrm{P} / \mathrm{P}=\mathrm{p})$. This can be determined by initially rewriting eq. (4.1.1) in terms of logarithms, differentiating the result with respect to time $t$, and re- arranging terms yielding

$\mathrm{P}(\mathrm{t})=\mathrm{m}(\mathrm{t})=\mathrm{bp}(\mathrm{t})$ 
Thus on, average, the growth rate of money is below the rate of inflation. This is because, following eq.(4.1.1), people are reducing their holdings of real balances during hyperinflation if $\mathrm{M} / \mathrm{P}$ is falling, then it implies that prices on an average must be increasingly more rapidly than money supply, i.e.

$\mathrm{p}(\mathrm{t})>\mathrm{m}(\mathrm{t})$, for all $\mathrm{t}$

Combining eq.(4.2.2) and (4.2.4) yields

$\mathrm{p}(\mathrm{t}+1)>\mathrm{m}(\mathrm{t})$ for all $\mathrm{t}$

which can be written as

$\mathrm{p}(\mathrm{t}+1)+\mathrm{a}\{\mathrm{m}(\mathrm{t})\}, \mathrm{a}>1$

\subsection{The government budget deficit}

The analysis so far has dynamically linked price increases during hyperinflation to the increases in the quantity of money. But there is still the question as to why the quantity of money increases by so large an amount during such times. The answer lies in the fact that all hyperinflationary economies have invariably suffered from very large budget deficit. In several cases, the origin of the budget deficit was war time spending which generated large national debts and also destroyed the tax- gathering apparatus of the country.

Thus, during hyperinflation, government spending in nominal terms $(G)$ rises astronomically in order to provide the government with real resources, contrariwise, tax revenue in nominal terms ( $\mathrm{T}$ ) falls rapidly due to lags in both the calculation and payment of taxes. .Therefore, the budget deficit (BD) which is defined as

$\mathrm{BD}(\mathrm{t} 0=\mathrm{G}(\mathrm{t})-\mathrm{T}(\mathrm{t})$

Rapidly starts getting out of hand. While the government can finance its deficit either through money financing or debt financing, the scope for the latter is extremely limited during hyperinflation. This implies that the government has no other altrernative but to print money in order to finance its deficit. Thus, we have,

$\mathrm{M}^{\prime}(\mathrm{t})=\mathrm{BD}(\mathrm{t} 0=\mathrm{G}(\mathrm{t})-\mathrm{T}(\mathrm{t})$

where $\mathrm{M}^{\prime}(\mathrm{t})$ is the increase in the stock of money in period t. dividing eq. (4.3.2) by money supply in period $\mathrm{t}, \mathrm{M}(\mathrm{t})$, yields

$\mathrm{m}(\mathrm{t})=\{\mathrm{M}(\mathrm{t}) / \mathrm{M}(\mathrm{t})\}=\{\mathrm{G}(\mathrm{t}) / \mathrm{M}(\mathrm{T})\}-\{\mathrm{T}(\mathrm{t}) / \mathrm{M}(\mathrm{t})\}$

Thus it is seen that the high rates of money growth, $\mathrm{m}(\mathrm{t})$, originate in attempt to finance the budget deficit.

\subsection{The inflation tax revenue}

In the chaotic condition during hyperinflation, governments are too weak to enact and effectively administer adequate tax programs. However, as the inflation rate rises, the real revenue raised from all nominal channels of taxation falls - the so called Tanzi - Olivera effect. Under such circumstances, the government resorts to the issuing of money as a method of raising revenue by a special kind of tax - the inflation tax - which is appealing because it does not require detailed legislation and can be administered very easily. All that is required is to spend newly printed money. The resulting inflation automatically imposes a tax on real balances by depreciating the value of money.

When the government finances its deficit by creating money, it in effect keeps printing money, period after period, which it uses to pay the goods and services it buys. This is absorbed by the public. The only reason as to why the public would choose to add to its holdings of nominal money balances, period after period, would be to 
offset the effects of inflation. When the public is thus adding to its stock of nominal balances, it is using part of the income to increase its holdings of nominal balances- and this amount is not available for spending. Inflation thus acts just like a tax because people are forced to spend less than their income and pay the differences to the government which thus has more resources to spend just as if it has raised taxes. When the government finances its deficits by issuing money, which the public adds to its holdings of nominal balances to maintain the real value of money balances constant, we say that it is financing itself through the inflation tax. The amount of inflation tax revenue in real terms is $\mathrm{T}(\mathrm{t}) / \mathrm{P}(\mathrm{t})$ from the inflation tax is therefore the product of the tax rate(the inflation rate) and the object of taxation (the real monetary base), i.e. ,

$\{\mathrm{T}(\mathrm{t}) / \mathrm{P}(\mathrm{t})\}=\mathrm{p}(\mathrm{t}) .(\mathrm{M} / \mathrm{P}) \mathrm{t}$

Substituting eq.(4.1.1) into (4.4.1) above, yields

$\{\mathrm{T}(\mathrm{t}) / \mathrm{P}(\mathrm{t})\}=\mathrm{p}(\mathrm{t}) \mathrm{e}^{-\mathrm{bp}(\mathrm{t})}$

Total revenue is the maximum when the first derivative of this expression with respect to $p(t)$ is zero and the second derivative is negative, i.e.,

$\mathrm{d}\{\mathrm{T}(\mathrm{t}) / \mathrm{P}(\mathrm{t})\} / \mathrm{dp}(\mathrm{t})=(1-\mathrm{bp}(\mathrm{t})) \mathrm{e}^{-\mathrm{bp}(\mathrm{t})}=0$

$\mathrm{d}^{2}\{\mathrm{~T}(\mathrm{t}) / \mathrm{P}(\mathrm{t})\} / \mathrm{dp}(\mathrm{t})^{2}=\left(\mathrm{b}^{2} \mathrm{p}(\mathrm{t})-2 \mathrm{~b}\right) \mathrm{e}^{-\mathrm{bp}(\mathrm{t})}<0$

these conditions are satisfied when

$\mathrm{bp}(\mathrm{t})=0$

Therefore, the rate of tax on real money balances, i.e., the inflation rate, yields the maximum inflation tax revenue in eq. (4.4.2) is equal to (1/b). At this rate of tax, the demand for real balances has an elasticity of -1 . This implies that the government does not set the tax rate directly. It just set the rate at which to increase the money supply, and this rate determines the tax rate through the process as described above.

To relate the inflation tax revenue collected in real terms with the budget deficit measured in nominal terms, we assume a one period lag in tax receipts and multiply eq. (4.4.2) by $\mathrm{P}((\mathrm{t}-1)$, to obtain the inflation tax revenue in nominal terms. This yields the equation

$\mathrm{T}(\mathrm{t})=\mathrm{P}(\mathrm{t}-1) \mathrm{p}(\mathrm{t}) \mathrm{e}^{-\mathrm{bp}(\mathrm{t})}$

Substituting eq. (4.4.5) into (4.3.3) yields

$\mathrm{M}(\mathrm{t})=\{\mathrm{G}(\mathrm{t}) / \mathrm{M}(\mathrm{t})\}-\{\mathrm{P}(\mathrm{t}-1) / \mathrm{M}(\mathrm{t})\} \mathrm{p}(\mathrm{t}) \mathrm{e}^{-\mathrm{bp}(\mathrm{t})}$

\subsection{The chaotic dynamics of hyperinflation}

The maximum revenue received by the government would thus be at the optimal inflation rate $\mathrm{p}^{*}=(1 / \mathrm{b})$. A higher inflation rate would not yield proportionately higher revenue, because real money balances would decline in response to the higher rate. Indeed, it would decline more than in proportion to the rise in the inflation rate, so that a higher rate would yield lesser revenue. When this happens, the deficit would start expanding and so would the money growth rates and, consequently, the economy would start inflating at successively higher rated. This would completely disrupt the economy, producing the characteristic pattern of hyperinflation: prices increases would explode.

Such a pattern can be observed by substituting eq. (4.4.6) into (4.2.6) in order to yield the following first order (transcendental) difference equation in the rate of inflation 
$\mathrm{p}(\mathrm{t}+1)=\mathrm{a}\left(\{\mathrm{G}(\mathrm{t}) / \mathrm{M}(\mathrm{t})\}-\{\mathrm{P}(\mathrm{t}-1) / \mathrm{M}(\mathrm{t})\} \mathrm{p}(\mathrm{t}) \mathrm{e}^{-\mathrm{bp}(\mathrm{t})}\right)$

We now make the following two substitutions:

$\mathrm{a}(\{\mathrm{G}(\mathrm{t}) / \mathrm{M}(\mathrm{t})\}=\varphi$

$\mathrm{a}\{\mathrm{P}(\mathrm{t}-1) / \mathrm{M}(\mathrm{t})=\theta$

This yields the following three parameter chaos theory model.

$\left.\mathrm{p}(\mathrm{t}+1)=\varphi-\theta p(\mathrm{t}) \mathrm{e}^{-\mathrm{bp}(\mathrm{t})}\right)$

A priori, it seems that such a model, in view of all the assumptions built into it, must exhibit instability and inflation, once triggered, should continue under its own momentum indefinitely. However, it will be shown that this is not true and, under alternative conditions, the ensuing inflation rates would either exhibit a chaotic trajectory or oscillate around a limit cycle or converge towards a fixed attractor.

\section{CONCLUSIONS}

The impossibility of obtaining analytical closed form solutions led us to perform numerical simulations in order to observe the progression of chaotic behaviour. The results proved that such a process of evolution is governed by the parameter $\varphi$ (defined as the ratio of government expenditure to money supply) whose value dictates the rapidity with which the transition from chaos to stability occurs, via the intervening phase of a two - period limit cycle which is explained in terms of a bifurcation of an existing unstable equilibrium solution. The possible existence of three equilibrium solutions yields certain vital conclusions regarding the self generating aspects of hyperinflation. Amongst these are (1) the high probability of chaotic behaviour at relatively low levels of, $\varphi$ (2) the possibility of sensitive dependence on initial conditions which determines whether a temporary equilibrium converges towards a stable solution or oscillates around a two - period limit cycle, and (3) the existence of a critical value $\varphi$ at which a prolonged hyperinflation, instead of damping down - as most often observed in real lifeexplodes towards a much higher rate.

\section{REFERENCES}

1. Baumol, W. J (1986) "Unpredictability, Pseudo- Randomness and Military - Civilian.

2. Baumol, W. J. and J. Benhabib. (1989) "Chaos: Significance, Mechanism, and Budget Interactions" Revista Internationale di Scienze economiche Commerciali XXXIII.

3. Benhabib, J. and R. H. Day (1981) "Rational Choice and Erratic behaviour" Review of Economic Studies, 48.

4. Benhabib, J. and R. H. Day (1982) "A Characterization of Erratic Dynamics in an overlapping Generation Model", Journal of Economic Dynamics and Control.

5. Blanchard, O. J., (2005) Macroeconomics, 4th ed. Prentice Hall, New Jersey Boldrin, M. and M. Woodford. (1990) "Equilibrium Models Displaying Endogenous Fluctuations and Chaos," Journal of Monetary Economics, Vol. 25,

6. Cagan, P. (1956) "The Monetary Dynamics of Hyperinflation" in M. Friedman (Ed).Studies in the Quantity theory of Money, The University of Chicago Press, Chicago.

7. Day R. H (1982) "Irregular Growth Cycles". American Economic Review , 72

8. Day, R. H. (1992) "Complex Economic Dynamics: Obvious in History, Genericin Theory, Elusive in Data" Journal of Applied Econometrics, Vol. 7.

9. Honkapohja, S., Mitra, K., (2006) "Learning Stability in Economies with Heteroge-neous Agents". Review of Economic Dynamics 9.

10. Jensen, R. U. and R. Urban (1982) "Chaotic Price Behaviour in Nonlinear Cobweb Model". Mimeo Yale University.

11. Lorenz E., (1963) "Deterministic non-periodic flow”, Journal of Atmospheric Sciences, 20 
12. Mankiw, N. G., Reis, R., and Wolfers, J., (2003) “Disagreement about Inflation Expectations”. NBER Macroeconomic Annual 18, 209-248.

13. Poincare, H. (1892) "Les Methodes Nouvelles de la Mecanique Celeste I, II, II, Gauthier - Villars, Paris

14. Rao, M. J. M. (1990) "The Chaotic Dynamics of Hyperinflation” project Document No. 9004 National Aeronautical laboratory, Bangalore.

15. Sarkovskii, A.N. (1964) "Coexistence of Cycles of a Continuous Map of a line into itself". Ukranichkii Mathematicheskii Zhurnal, 16.

16. Stutzer, M. (1980) "Chaotic Dynamics and Bifurcation in a Macro Model". Journal of Economic Dynamic and Control, 2.

17. Westerhoff, F., (2006 b) "Business Cycles, Heuristic Expectation Formation and Contra-cyclical Policies". Journal of Public Economic Theory 8.

18. Westerhoff, F., Reitz, S., (2003) Nonlinearities and Cyclical Behavior: the Role of Chartists and Fundamentalists. Studies in Nonlinear Dynamics and Econometrics 7, no. 4, article 3. 